\title{
Simulated medical consultations with standardized patients: In-depth debriefing based on dealing with emotions.
}

\author{
Simulação de consultas médicas com pacientes \\ padronizados: utilizando um debriefing \\ aprofundado baseado nas emoções do paciente e \\ do estudante.
}

\section{KEYWORDS: \\ - Professionalism \\ - Patient Simulation \\ - Formative Feedback}

\author{
Marcelo Schweller \\ Diego L. Ribeiro ${ }^{I}$ \\ Sílvia R. Passeri ${ }^{I}$ \\ Jamiro S. Wanderley \\ Marco Antonio Carvalho-Filho
}

\begin{abstract}
In general, students have few opportunities to address their emotions under the guidance of an experienced physician, which can undermine their self-confidence to deal with real patients in stressful situations. Emotional detachment and cynicism are defense mechanisms, which can emerge as a consequence. The consolidation of a professional identity committed to patients' interests can become a challenge when medical students are not comfortable in their role as caregivers. In general, we consider that the undergraduate medical curriculum has been insufficient in providing appropriate environments for students to reflect on professional identity formation and on the future challenges of their profession. Objective: To develop an in-depth debriefing to address students' emotions and professional identity formation in the context of a simulation activity with simulated patients at a medical school in Brazil. Methods: The authors conducted a simulated medical consultation activity using standardized patients (SPS) with an in-depth debriefing based on the feelings of the patient and the student. During each encounter the formation and consolidation of professional identity was discussed. Fourth-and sixth-year medical students $(n=551)$ participated and answered a questionnaire about the activity and the learning outcome. Results: The students felt comfortable during the activity, due to "openness to dialogue", "proximity with colleagues and teachers" and the "judgment-free environment". More than 90\% reported that what they had learned would be useful in their professional and personal lives, providing a greater "understanding of emotions", "empathy", "ability to listen" and "ability to deal with conflicts". More than half of them were motivated to study, especially "doctor-patient relationship", "treatment", "common diseases" and "medicine in general". Students considered the activity important for retrieving the initial reasons that had led them to embarking on the medical profession in the first place. Conclusions: Reflecting on disease and its impact on patients' daily life may motivate learning in medicine, allowing for the recovery of the personal and social meaning of its practice. In-depth debriefing was important to nurture professional identity committed to empathy and patients' interests. Activities planned to discuss the influence and importance of emotions in medical practice can help students to reconcile personal and professional identities.
\end{abstract}




\section{PALAVRAS-CHAVE:}

- Profissionalismo

- Simulação de Paciente

- Feedback Formativo

Recebido em: 20/4/17

Aceito em: 19/11/17

\section{RESUMO}

Em geral, os estudantes de medicina têm poucas oportunidades para refletir sobre suas emoções guiados por um médico mais experiente, e isto pode levar a uma diminuição da sua autoconfiança para lidar com pacientes reais, particularmente em situações de estresse. Como consequência podem surgir o distanciamento emocional e o cinismo. Neste contexto, a consolidação de uma identidade profissional comprometida com os interesses do paciente pode ser um desafio se os estudantes não estiverem confortáveis em seus papéis de cuidadores. Muitas vezes, o currículo médico não cria oportunidades suficientes para refletir sobre o desenvolvimento da identidade profissional e sobre os desafios da prática médica futura. Objetivo: Desenvolver um debriefing estendido e profundo para abordar a dimensão afetiva das consultas médicas e a formação da identidade profissional no contexto de uma atividade de simulação com pacientes padronizados em uma escola médica no Brasil. Métodos: Os autores conduziram uma atividade de simulação de consultas médicas com paciente padronizado com um debriefing estendido baseado nas emoções do paciente e do estudante. Durante cada um dos encontros a formação e consolidação da identidade profissional foram abordadas. Alunos do quarto $e$ sexto ano médicos $(n=551)$ participaram das atividades e responderam um questionário sobre a atividade e sobre os objetivos alcançados. Resultados: Os estudantes sentiram-se confortáveis durante a atividade devido a "abertura para o diálogo", "proximidade com professores e colegas" e um "ambiente livre de julgamentos". Mais de 90\% dos estudantes considerou que o aprendizado será aplicado tanto em suas vidas profissionais como em suas vidas pessoais, por um maior "entendimento das emoções", "empatia", "habilidade para ouvir" e "habilidade para lidar com conflitos". Mais da metade dos estudantes sentiu-se motivada a estudar, especialmente "relação médico-paciente", "tratamento", "doenças comuns" e "medicina em geral". A atividade foi considerada importante para resgatar a motivação inicial que os levaram a escolher o curso médico. Conclusões: Refletir sobre as doenças e seus impactos na vida dos pacientes pode motivar os estudantes a aprender medicina, permitindo o resgate do significado pessoal e social de sua prática. O aprofundamento do debriefing foi importante para nutrir uma identidade profissional comprometida com a empatia e com os interesses dos pacientes. Atividades planejadas para abordar a influência e a importância das emoções na prática médica podem ajudar os estudantes no processo de reconciliação entre suas identidades pessoal e profissional.

\section{INTRODUCTION}

The traditional medical school curriculum is based on two components: one theoretical, made up mainly of expository lessons, and the other practical, based on learning in real situations, at the bedside.

Throughout the past several decades, there has been a sharp increase in the production of medical knowledge, as well as a genuine revolution in the way through which this knowledge is disseminated ${ }^{1}$. New generations of students consume this information while simultaneously engaging in other online activities, but this multitasking can decrease the student's capacity to reflect on what is being learned and on the meaning of each activity ${ }^{2}$. Dealing with emotions is one of the most challenging components of being a physician. Although there are some regular courses on communication skills and human- ities, most medical curricula fail to address this issue directly ${ }^{3}$. In general, medical students learn by themselves how to cope with this important dimension of medical practice.

In this context, undergraduate medical education should incorporate new teaching methods to promote a safe environment for reflection, an essential aspect of lifelong learning ${ }^{4}$. Among the various techniques available for learning new competencies, simulation has been incorporated into the curriculum at various schools, and its importance has already been consolidated in a few areas of medical education ${ }^{5}$, such as in emergency medicine training ${ }^{6}$.

The participation of standardized patients (SP) in simulation activities has increased ${ }^{7}$, especially for training in specific competencies related to physical examinations, communication and assessment in objective structured clinical examina- 
tions (OSCE). However, medical consultation is an extremely complex interaction, which involves, among other competencies, the formation of a meaningful bond, empathy, and negotiation of a shared treatment plan. These more complex elements have not yet been extensively explored through practical activities in the training of undergraduate medical students and residents.

Recently, professional identity formation has gained value as an individual goal of medical education and this new concept allows teachers to incorporate the necessary nurturing of specific values and virtues to curricular and course design ${ }^{8,9}$. Another consequence of this new concept is the ongoing reframing of our assessment goals and objectives, which need to address the complexity of becoming a full professional ${ }^{10,11}$. This new approach highlights the crucial role of our social contract, which is to put patients' interests first, while being committed to the main principles of bioethics: autonomy, beneficence, no maleficence, justice and equity. We believe that formally addressing these issues in the medical curriculum can counterweigh the impact of the hidden curriculum and negative role models on students' attitudes and behaviors.

With this in mind, we developed a medical consultation simulation activity with SP with the purpose of providing training for the real practice of medicine. The clinical cases had a mixture of technical and humanistic challenges related to the doctor-patient relationship, demanding different competencies from the students. Moreover, we ensured that the patient's emotions related to the disease and to the doctor would always be made apparent during the consultations.

In parallel, we developed an extended debriefing based on emotions, with intensive reflection on the values and virtues of the medical profession, developing an awareness of the process of professional identity formation. The simulated consultations were triggers to bring emotions to the debate and to allow facilitators to share with students the importance of being aware of emotions and their impact on clinical reasoning and the doctor-patient relationship. Students could understand that emotions are natural and that it is important for the physician to deal with emotions in a positive way, protecting patients' interests and values. The environment was safe, free of pejorative and negative judgments and facilitators and students were able to share their experiences and understandings. The duration of each encounter was variable, ranging from three to five hours. Students could bring their own issues to the discussion and we used it as a parallel between the role of a physician and the role of a teacher. If we want to teach students how to be available for their patients' demands, we also must be available for student demands.
The objective of this project was to record the opinions of students on this kind of training and to assess the impact of the activity on their perceptions of their role in the doctor-patient relationship and on their personal and academic behavior. We were also interested in observing how students would cope with an activity dedicated to discussing patients' emotions and their own emotions as physicians and as medical students. We hypothesized that students had scarce curricular opportunities to reflect on that, particularly with the guidance of experienced physicians, based on real clinical situations, when emotions are intense and uncontrolled.

\section{METHODS}

The research project was submitted to the Research Ethics Committee on Human Beings at the Faculty of Medical Sciences of the University of Campinas (Unicamp), which granted the due ethical approval (896/2010 - CAAE 0692.0.146.000-10).

\section{Participants}

The study was carried out with 551 fourth- and sixth-year students at a medical school in Brazil. The fourth-year students $(\mathrm{n}=111)$ participated in the simulation activity voluntarily in 2011 and 2012, while the sixth-year students $(n=440)$ participated through their curricular rotation in emergency medicine from 2011 to 2015 .

\section{Context}

The undergraduate medical course at our institution takes 6 years. The beginning of the course includes basic sciences and an introduction to patient care; the third and fourth years are known as "clinical study", when students begin to perform consultations; and the two final years are dedicated to learning in practice in the major areas of medicine.

In their sixth-year, students have a mandatory Emergency Medicine rotation lasting two months. They are directly introduced into patient care at the Emergency Department, the Emergency Ward and the Intensive Care Unit, with constant supervision of physicians and professors. In this rotation, students face the challenges of the medical profession in a public health system and engage with the suffering of patients and their families. Therefore, it would be interesting to offer students, during this period, a dedicated time for them to reflect on these challenges with the guidance of experienced teachers.

\section{Standardized Patients}

The use of standardized patients in medical education has been well described in Brazilian ${ }^{12}$ and international ${ }^{13}$ literature. 
They are usually represented by lay people, often the teacher or other students (peers). Since our idea was to simulate a complex interaction, that is, a medical consultation, we decided to recruit a group of professional actors with experience in education for this activity. Initially, we presented to them the idea and objectives of the course, emphasizing its formative character. Then, teachers elaborated the clinical cases and a script was passed on to the actors, so that they could develop the corresponding personal and familiar characteristics necessary to transmit veracity to the case. Furthermore, from the outset the patients already had a well-established emotional atmosphere, so that the situations and emotions that we wanted to discuss during the debriefing would emerge in the consultations.

The performance took place in a realistic way, and sought to faithfully reproduce a real consultation. Nevertheless, it is worth mentioning that in the simulated consultations the challenges are planned to arise, which is not always the case in real consultations, in which the patient may be inhibited for several reasons and not share some issues.

After this initial phase, we tested the cases through simulated consultations between the teachers and actors with the purpose of developing the patients' stories, discussing the themes involved and predicting the students' possible reactions when faced with each situation. The main concern about building the cases was to assure that patients' emotions would be present in each simulation activity, regardless of the student's performance. Our main purpose was to shed light on the effect of emotions on students' behavior during and after consultations, while reflecting on their performance.

\section{Facilitators}

During the development phase of this activity, we discussed situations from our real clinical practice, with special emphasis on the doctor-patient relationship. These discussions were essential in defining the main themes to be approached with the students and attempting to objectively formulate questions that were present in our day-to-day practice. We reflected on what our main difficulties and concerns were, when dealing with patients' emotions and on what were the most challenging situations related to that. It could be really challenging not being judgmental while observing and discussing students' performance in this kind of case.

In this context, it was important to be aware of our attitudes as teachers, especially of our reactions and attitudes towards the students' roles, both in simulated consultations and in the debriefing. We concluded that, if one of our core messages was the importance of avoiding preconceived ideas and judgments with regard to the patient, it would be necessary that we, as teachers, be trained not to make negative or moral judgments towards students. Thus, it was possible to conduct the discussions with an emphasis on positive reinforcement, which allowed us to approach difficult topics about the doctor-patient relationship, hidden curriculum and professional identity formation.

\section{Simulation of Medical Consultations}

The activity was performed in groups from seven to nine students in four weekly meetings throughout 2011-2015. In each of the meetings, the SP was seen by two students individually and sequentially, that is, while the first student was seeing the patient, the second waited outside the environment in which the activity was performed. The rest of the group (other students and facilitators) watched these consultations in an adjoining room through a closed-circuit television (CCTV) system. The facilitators who participated in the activity were working with the students in the emergency unit and the internal medicine infirmary and leading the simulation activities.

The clinical cases utilized were fictitious but based on various real outpatient care situations. All the cases involved feelings related to the disease and its consequences to the relationship of patients with their family, society and their own life story, and were built to evoke deep emotions in the patient and in the physician.

The clinical situations are shown in List 1 and included breaking bad news to a person with whom we have positive countertransference, comforting an angry patient, motivating demotivated patients with chronic diseases, dealing with a patient's refusal to notoriously efficient treatments, and helping the patient with end-of-life decisions.

\section{Debriefing}

After a short break, students would share with the group their initial feelings regarding the consultation that they had just experienced and would make a summary of the clinical case. The students' own speech, always rich in clues, worked as a trigger for discussion of the topics that had been planned. Furthermore, other themes based on the needs of each student and each group frequently came up.

The main reflection made in the debriefing revolved around the importance of realizing the frailty of the patient when faced with his or her disease. A diagnosis and its prognosis bring unplanned changes in the patient's life, possibly setting off emotions like fear, guilt and helplessness. The patients react to these emotions in different ways, showing 
indignation, sadness or even anger, a feeling that may be directed towards the physician. These reactions may confuse the young physician, who is not always alert to the hidden feelings that lie behind a patient's negative or even bad attitude.

Because of the complexity of the topics discussed and the reactions of the students, who often became emotional and shared their difficulties, the debriefing lasted, on average, 2 to 3 hours per meeting and sometimes even 4 hours. The safe environment created allowed students to bring issues related to negative role models and to the hidden curriculum. During this time, we could discuss the role of emotions in clinical practice, and their influence on our relationship with the patient. Students could also reflect on the importance of being aware of this process. At the same time, we could challenge students with these two questions: "What kind of physician do you want to be?" and "What kind of medicine do you want to practice?". These questions were important for inducing awareness about the process of professional identity formation, while inviting students to reflect on the influences they had suffered along their journey as medical students. The students frequently discussed how they were reproducing clinical and ethical behaviors without properly reflecting on them, just imitating some of their negative role models.

\section{Instrument and Data Analysis}

On the last day of the activity, following the debriefing, the students filled out an anonymous questionnaire in which they were asked to score on a scale from 1 to 10 the activity as a whole, and specific aspects of it, like the facilities, the realism of the scenes, the acting and the feedback from the facilitators. Moreover, they answered questions about how they felt during the activity and about its impact on their professional and personal lives. These questions had as possible answers "yes", "no" and "indifferent", and were recorded and analyzed.

After certain questions, there was space for the students to explain their answers or write comments. These questions were: (1) "Did you feel comfortable during the feedback? Why?"; (2) "Do you think you will use what you have learned in your professional life? How?"; (3) "Do you think you will use what you have learned in your personal life? How?"; (4) "Did this simulation activity motivate you to study? Study what?".

After the anonymous questionnaire, students were invited to give their feedback directly to the facilitators. These sessions were most of the time very emotional meetings with a genuine feeling of being part of a community.

The students' answers were read by the authors, categorized and then classified based on most frequent to least frequent. Some complete sentences written by the students, which seemed most representative of the opinions of the group were selected and transcribed in full in this report.

\section{RESULTS}

The 551 fourth and sixth year medical students rated particular elements of the activity, and these results can be found in table 1, below.

The following questions addressed students' perceptions of other aspects of the simulation activity and of the impact of what they had learned on their academic and professional daily lives. These results can be found in table 2 .

We noted that, given the exposure involved in performing a filmed emotional consultation and being observed by classmates and professors, the vast majority of students felt comfortable during the simulated consultation and were able to get involved with the scenes, despite their being simulated. During the debriefing, $96 \%$ of students felt comfortable, even when discussing emotions related to patients. The main reasons given to explain this feeling were (1) openness to dialogue, (2) proximity of classmates and teachers, (3) a constructive environment and (4) absence of judgment. Some responses which can exemplify these reactions:

\section{"I realized that I have much to improve, but I see a positive outlook regarding this". \\ "These simulation activities have brought back my confidence and enthusiasm to practice medicine, reinforcing to me that it is more than a science, it is an art: the art of listening, thinking, talking, living and planning."}

In the opinion of more than $95 \%$ of the students, the activity had a positive impact on their ability to listen to patients, and to more than $91 \%$ this impact also extended to the ability to listen to others in general. When asked about the effect of the activity on their interactions with their classmates within the simulation group, around $75 \%$ of students reported a positive impact. Sometimes, during the debriefing, students reported that throughout the week they encountered real situations to which they were able to apply their ability to listen to patients or listen to others and that this brought them personal satisfaction.

"This activity was very important for my process of professional and personal formation since I learned to regard the patient from different perspectives. After this opportunity to reflect, I believe that I can put myself in patients' shoes 
and better understand the reason for their anguishes, their difficulties in dealing with their diseases, their guilty feelings and fears. Thank you very much for this opportunity."

When asked about the practical applicability of the activity, $100 \%$ of the students reported that they would apply what they had learned to their professional lives and more than 93\% reported that they would also apply it to their personal lives, through the following competencies: (1) understanding emotions, (2) empathy, (3) ability to listen, and (4) ability to deal with conflicts. The following responses written by students characterize these attitudes:

"I believe that I will apply what I learned to my personal life, paying attention to the real needs of others rather than what I think is important";

"The doctor-patient relationship is an exercise in improving your relationship with anyone. It makes you a better person, more willing to listen".

"It is important to realize that myself and what I know are not the main issue during a consultation, but the truth is that I am there to listen, and to help patients to find a meaning in the context of their disease and its treatment."

When we asked if the activity had brought motivation to study, $67 \%$ of fourth-year students and $58 \%$ of sixth-year students responded in the affirmative, especially for the topics of (1) the doctor-patient relationship, (2) treatment, (3) most prevalent diseases and (4) medicine in general. One response that exemplifies these answers was as follows:

"I believe that the doctor with more knowledge is more confident, so I think that the activity motivated me to study everything, in general".

"This activity shows us a kind of medicine that is not learned from the books. We are always amazed by the quality of our teachers' consultations and now we can see that this quality is possible not only due to their technical competence, but also because they master a kind of relationship art - an art we can learn and must use. We have learned the pathway to become as good as those we admire, and this will benefit our patients."

In the final space of the questionnaire, set aside for comments and spontaneous remarks from the students, there were several very significant responses from the students, two of them being as follows:

\begin{abstract}
"A more humane contact and special attention to each patient reaffirms your passion for medicine and reminds you of the somewhat utopian views of the first year, which are often lost throughout the years and the infirmaries".
\end{abstract}

\begin{abstract}
"We accept a routine very easily, without reflecting on what we are doing. The need to reflect constantly was the greatest lesson I have taken out of these meetings. Besides, issues on how to deal with patients and their reactions have elicited many new possibilities about the kind of professional I want to be; about the possibility of being glad and pleased even while dealing with sadness and death. I had very few opportunities during the undergraduate course to deal with these fundamental questions in such an honest and enlightening way. My willingness to become a doctor has been enhanced. Thank you!"
\end{abstract}

It is worth emphasizing that, during the meetings with most groups, the students frequently brought up the need to talk about the hidden curriculum, often in an intense and emotional way. They shared with us the difficulty that they had in building their own way of practicing medicine when exposed to examples of negative role models, and its consequences to their academic, professional and personal satisfaction.

\footnotetext{
"Sadness was consuming me. During the outpatient clinics rotations of my undergraduate course I was losing the capacity to listen, to understand and to see the patient holistically. I was losing my loving way and even becoming cruel with my patients. The happiness I used to feel in learning to be a doctor, capable of helping people, was replaced by anger and "1 minute" consultations. Lately, coming to the hospital was making me feel resentful. During these activities, I have again realized that I can treat people with the dignity they deserve, and I can love what I am doing. I now understand that I can make the difference for my patients, and this is what I want to do."
}

During the last session, when students provide their feedback on the activity, the main theme was how they did not yet have a personal way of practicing medicine. Students stated that eventually their ethical and clinical behavior was molded in accordance with the expectations of the professor responsible for the clinical rotation they were in. In other words, they hadn't yet got control over their professional identity. This 
discovery was accompanied by a feeling of freedom and autonomy, rescuing some values and virtues that had motivated the students to choose medicine as a career in the first place.

\begin{abstract}
"As I did at the beginning of the medical course, I believe again that it is possible for me to become the physician I once dreamed about; to love my patients and, at the same time, offer them the adequate medical and technical care."

"This activity made me reconsider the role of the physician, the purpose of the medical profession, and the kind of professional I want to be."
\end{abstract}

"I want to practice medicine for my entire life, falling in love again and again with the only profession I can have."

\section{DISCUSSION}

The use of simulation as a teaching tool in medicine has grown along with discussions of patient safety ${ }^{14-16}$, and students recognized the importance of prior training to clinical practice. Nevertheless, the fact of being filmed and exposed to the observation of classmates and teachers may cause discomfort and embarrassment ${ }^{17}$ during the simulated consultations and the debriefing, potentially limiting the effectiveness of this kind of activity.

In our study, however, the vast majority of students felt at ease during the simulated consultation and were able to engage in the scenes. We believe that this result may be partly due to the clear exposure of the objectives of the activity before its beginning, and the clarification that the intervention was purely formative and not summative. Sharing with the students the goal of addressing the affective aspects of clinical practice was important to prepare them to face patients' emotions during the simulated consultations.

Similarly, our students felt comfortable during the debriefing thanks to the openness to dialogue, the proximity with classmates and teachers, the constructive environment and the absence of judgment. We thus realized that the performance of the simulation activity by teachers who also work with students in real clinical practice situations might be a positive factor for the effectiveness of the course, due to both their proximity to the students and the understanding that the doctor-patient relationship is real, not merely theoretical and idealized. Since we are advocating the necessity of dealing with patients' emotions in a positive and constructive way, it is mandatory that facilitators do the same with students' emotions during the debriefing.
Furthermore, the effort to foster a debriefing environment that was free, safe, devoid of judgment, and based on positive reinforcement seemed to allow students to share their experiences and their thoughts. This kind of environment is, in our opinion, the same that must exist between the doctor and the patient during a consultation, so that the patient feels at ease to share his or her experiences and thoughts, and so that the doctor has the legitimacy and intimacy necessary to make suggestions and comments that make sense to the patient's life. Therefore, students were able to understand that the abilities required to create a safe environment for sharing experiences, emotions and concerns are universal and not only related to medical profession.

The act of listening during the medical consultation has well-established benefits ${ }^{18}$. The simulation activity, according to the students, improved their ability to listen to the patient and to listen to others in general. This result may be partly due to the training in communication abilities, but we had the impression that, during the simulated consultations and the debriefing, the students were able to realize that truly listening brings immediate results to the doctor-patient relationship and to the outcome of consultations. Subjectively, we confirmed our hypothesis that to motivate the medical students to listen, we would have to create an environment in which the students themselves were heard. Besides that, students could notice that when patients are facing difficult moments and emotions are driving their behavior, non-verbal communication is particularly important, and even moments of silence are potentially full of meaning.

This predisposition to listen to and notice others may also explain the results obtained in terms of the improvement in the students' interaction with participants of the activity. We noticed that, over the course of the weeks, the students displayed growing confidence in sharing their ideas and troubles and reported to us that this change occurred outside the context of the simulation activity as well. To accept the differences between the patients and ourselves as doctors is a sort of training to deal with differences in general. The opportunity to understand the motives of our patients' behavior can enlighten the importance of empathy and can drive us in the direction of humility and away from prejudice and intolerance.

The students reported that they believed that they will use what they had learned in their professional and personal lives. The first question that emerges from this is whether it is even possible to separate our lives as physicians from our personal lives. Work is an important part of our lives and is intertwined with our perception of the future. In addition to taking up much of our time, it offers us the social and finan- 
cial conditions to plan our lives as a whole. We believe that an accomplished professional has a greater chance of being a fulfilled person. Our students had the opportunity to reflect on the necessity of developing a professional identity fully committed to virtues and values of the medical profession and, at the same time, in complete harmony with our personal beliefs. They could discuss this issue with professionals who had already accomplished it.

In this same context, the students realized that many of the factors that improve our clinical practice and doctor-patient relationship could also improve our personal lives and our other relationships. When asked to explain how they believe they will apply what they have learned in their personal lives, the main categories of answers given by students were "understanding emotions", "having empathy", "listening" and "dealing with conflicts". We believe that it could represent a reconciliation between personal and professional identities, made possible by reflection on positive aspects of our professional development that can contribute to our personal lives.

During the debriefing, we had intense discussions about the impact of disease on patients' lives, and how all of their convictions, objectives and values could be questioned by the prospect of living with the disease. This causes a feeling of frailty, and the attentive doctor may, initially, understand and validate this feeling, and then offer positive suggestions that may help the patient deal with this challenge. In this way, the doctor acts supportively in the rebuilding of relationships and the meaning of things, which is fundamental for the patient to come to believe that happiness remains possible in the context of the disease.

In discussing these elements of the doctor-patient relationship during the debriefing, the students naturally had insights regarding how to conduct their consultations in the future. They noticed that it is often not enough to run down checklists of exam results and that treatment goes beyond prescribing medicine. This approach may explain the increase in motivation reported by students to study various aspects of the medical profession, as they understand that the nature of our profession is complex and that the necessary competencies to perform it should not be limited to just the technical aspects of treatment.

About 30 to $40 \%$ of the students answered they had not been motivated to study by the simulation activity. This could indicate that for this significant portion of the students the activity was not a positive and motivating experience. Although it is impossible to prove, after evaluating the questionnaire as a whole we believe that this is not likely, since more than $90 \%$ of the students reported positive im- pact of the activity in their personal and professional lives. Our hypothesis is that as we deal with difficult and intense issues, and participants often notice important things about themselves, the first impact of the activity may be the need for reflection rather than study itself. Even so, it is clear that the proposed didactic intervention may not be profoundly touching for all of the students.

A larger share of fourth-year students reported being motivated to study with the simulation activity. The other items in the questionnaire also showed a modest trend of more positive answers from these students compared to those in the sixth year. Although the difference is small, it may indicate that students at an earlier stage of formation may be more open to the impact and influence (positive or negative) of didactic interventions.

The deepening of the discussion of the social and cultural role of the physician brought to light the topic of the hidden curriculum, that is, the set of unplanned influences that medical students experience throughout the undergraduate course $^{19}$. The process of developing the professional identity of these students is under the influence of the hidden curriculum and the latter may have a negative impact on their future professional identity ${ }^{20}$.

Among the factors that constitute the hidden curriculum, role models are probably the most important. During the medical program, negative role models teach emotional distance as the best way of dealing with the conflicts inherent to our professional activities. The resultant cynical attitude, in addition to being ineffective for patients' outcomes, also compromises the doctor's own professional fulfillment. This served as an opportunity to share with the students the fact that there are other ways of dealing with difficulties encountered during the practice of medicine, and that professional maturity, together with reflection, bring more effective and fulfilling answers to the questions that emerge in our daily work as doctors. We believe that this kind of activity could be offered to students along the clinical rotations as a strategy to prevent the negative influence of certain role models that are in personal conflict with the medical practice. Simulation activities are well defined to address technical aspects of clinical practice, mainly related to patient safety and teamwork. We are proposing that simulation activities could also address "students' safety", preventing the development of the cynical behavior related to emotional detachment, learned from negative role models.

We also believe that professional identity formation may be addressed by simulation activities ${ }^{21}$. It is possible to create complex clinical scenarios, in which we discuss not only 
the technical aspects of medical practice, but also the affective, ethical and moral aspects of our decisions and attitudes. It is important to deal with all these dimensions at the same time, as well as dealing with the real practice. Helping the students deal with this complexity in a safe simulated scenario will help them develop a professional identity fully committed to the values and virtues of the medical profession. We realized that medical students sometimes do not behave properly not because they have low ethical or moral standards, but solely because they do not know how to, because they have not had the opportunity to reflect on what they are doing as doctors. As Aristotle stated a long time ago, virtue is practical wisdom, which demands practice to be learned and internalized.

\section{Challenges and study limitations}

There are some difficulties and challenges related to this type of didactic activity. The first is the availability of the physical structure and equipment for filming and broadcasting audio and video. In our case, the structure improved over time, and in the beginning we had to adapt to the contingencies of the moment, often improvising in order to be able to offer the activity.

The second challenge was to hire and train the team of actors. As we chose to work with professional actors because of the complexity of medical consultations, institutional support was necessary for financial reasons. In addition, since the participants in the activity often share personal experiences and feelings, it was fundamental to discuss with the actors the importance of confidentiality and respect for the formative nature of the intervention.

A third challenge was faculty development. Teachers who participated as facilitators already had an interest in these topics and clinical experience as physicians. However, formal training in simulation as a teaching methodology was crucial to define teaching goals, to construct the scenarios, and to conduct the debriefing. Furthermore, the complementary training of teachers with non-medical literature, philosophy and arts greatly contributed to enriching the discussions.

In proposing such an activity, it is crucial that teachers have the time and dedication to allow the discussion to deepen. As described, each debriefing can last for several hours, and it is not uncommon for students to get emotional or cry, for example. Therefore, it seemed important to us that the willingness to help students was not limited to the duration of the activity, so that some personal difficulties could be addressed in a more individual way. At times, this support was accompanied by a follow-up recommendation in the psychological support service of our institution.
The insertion of this simulation activity in the curriculum of sixth-year students was natural, since the clinical emergencies rotation in which it takes place is coordinated by the teachers who carried out the activity. For the students from the fourth year, the activity was carried out on an optional basis, lasting only two years. Its continuation was offered, but it was not possible to adapt the curriculum to include it.

There are limitations related to the kind of questionnaire that we used. When we ask a question about something that the students were not aware of, we may be inducing a positive answer, which would overestimate the quantitative results of this study. Besides that, medical students are often motivated by innovative teaching methods, and the use of SP and technology in our activity may also have inflated our positive results. Students quickly understand what teachers want in order to adapt their performance, and this could drive and influence our positive results. In addition, the evaluation was performed only once at the end of the activity, limiting our knowledge of possible long-term effects.

\section{Concluding Remarks}

The doctor-patient relationship is a complex interaction and demands various competencies from the doctor. To address this theme, didactic interventions should go beyond communication skills, and activities such as the simulation of medical consultations with standardized patients may be a way to deal with students' and patients' feelings. This type of intervention was well accepted by the students, who believe that they will use what they have learned in their professional and personal lives. Besides, encouraging reflection and openness to dialogue bring to light the hidden curriculum, negative role models and their impact on professional identity formation.

\section{REFERENCES}

1. Frenk J, Chen L, Bhutta ZA, Cohen J, Crisp N, Evans T, et al. Health professionals for a new century: transforming education to strengthen health systems in an interdependent world. Lancet 2010; 376(9756):1923-58.

2. Roberts DH, Newman LR, Schwartzstein RM. Twelve tips for facilitating Millennials' learning. Med Teach 2012; 34(4):274-8.

3. Abe K, Evans P, Austin EJ, Suzuki Y, Fujisaki K, Niwa M, et al. Expressing one's feelings and listening to others increases emotional intelligence: a pilot study of Asian medical students. BMC Med Educ 2013; 13:82. 
4. Sandars J. The use of reflection in medical education: AMEE Guide No. 44. Med Teach 2009; 31(8):685-95.

5. Okuda Y, Bryson EO, DeMaria S, Jacobson L, Quinones J, Shen B, et al. The utility of simulation in medical education: what is the evidence? Mt Sinai J Med 2009; 76(4):330-43.

6. Weller JM. Simulation in undergraduate medical education: bridging the gap between theory and practice. Med Educ 2004; 38(1):32-8.

7. Levine AI, Swartz MH. Standardized patients: the "other" simulation. J Crit Care 2008; 23(2):179-84.

8. Cruess RL, Cruess SR, Boudreau JD, Snell L, Steinert Y. Reframing medical education to support professional identity formation. Acad Med 2014; 89(11):1446-51.

9. Wynia MK, Papadakis MA, Sullivan WM, Hafferty FW. More than a list of values and desired behaviors: a foundational understanding of medical professionalism. Acad Med 2014; 89(5):712-4.

10. Cruess RL, Cruess SR, Steinert Y. Amending Miller's Pyramid to Include Professional Identity Formation. Acad Med 2016; 91(2):180-5.

11. Cruess RL, Cruess SR, Boudreau JD, Snell L, Steinert Y. A schematic representation of the professional identity formation and socialization of medical students and residents: a guide for medical educators. Acad Med 2015; 90(6):718-25.

12. Troncon LEA. Utilização de pacientes simulados no ensino e na avaliação de habilidades clínicas. Medicina (Ribeirão Preto) 2007; 40 (2):180-91.

13. Cleland JA, Abe K, Rethans JJ. The use of simulated patients in medical education: AMEE Guide No 42. Med Teach 2009; 31(6):477-86.

14. Nishisaki A, Keren R, Nadkarni V. Does simulation improve patient safety? Self-efficacy, competence, operational performance, and patient safety. Anesthesiol Clin 2007; 25(2):225-36.

15. Aggarwal R, Darzi A. Simulation to enhance patient safety: why aren't we there yet? Chest 2011; 140(4):854-8.

16. Griswold S, Ponnuru S, Nishisaki A, Szyld D, Davenport $\mathrm{M}$, Deutsch ES, et al. The emerging role of simulation education to achieve patient safety: translating deliberate practice and debriefing to save lives. Pediatr Clin North Am 2012; 59(6):1329-40.

17. Brimble M. Skills assessment using video analysis in a simulated environment: an evaluation. Paediatr Nurs 2008; 20(7):26-31.
18. Jagosh J, Donald Boudreau J, Steinert Y, Macdonald ME, Ingram L. The importance of physician listening from the patients' perspective: enhancing diagnosis, healing, and the doctor-patient relationship. Patient Educ Couns 2011; 85(3):369-74

19. Lempp H, Seale C. The hidden curriculum in undergraduate medical education: qualitative study of medical students' perceptions of teaching. BMJ 2004; 329(7469):770773.

20. Martimianakis MA, Michalec B, Lam J, Cartmill C, Taylor JS, Hafferty FW. Humanism, the Hidden Curriculum, and Educational Reform: A Scoping Review and Thematic Analysis. Acad Med 2015; 90(11 Suppl):S5-13.

21. McLean M, Johnson P, Sargeant S, Green P. Simulated patients' perspectives of and perceived role in medical students' professional identity development. Simul Healthc 2015; 10(2):85-91.

\section{ACKNOWLEDGEMENTS}

Declaration of interest: The authors report no conflicts of interest. All authors have read and approved the final manuscript and agree to the submission of the manuscript to the RBEM. Financial support for this study was received from the State of Sao Paulo Research Foundation (FAPESP) and the National Counsel of Technological and Scientific Development $(\mathrm{CNPq})$.

\section{NOTES ON CONTRIBUTORS}

\section{MARCELO SCHWELLER, MD, PhD}

mschweller@gmail.com

SILVIA MARIA RICETO RONCHIM PASSERI, PhD

spasseri@fcm.unicamp.br

MARCO ANTONIO DE CARVAHO FILHO, MD, PhD,

macarval@fcm.unicamp.br

\section{ENDEREÇO DE CORRESPONDÊNCIA}

Correspondence should be addressed to Dr. Carvalho-Filho, Departamento de Clínica Médica, Faculdade de Ciências Médicas, Universidade Estadual de Campinas (Unicamp), Rua Tessália de Vieira Camargo, 126, Cidade Universitária Zeferino Vaz, Campinas-SP, CEP 13083-887, Brazil. 